\title{
Caracterização Genética de Amostras de Conyza sp. do Estado Do Paraná ${ }^{1}$
}

\author{
Genetic Characterization of Conyza sp. Samples in the State of Paraná \\ CIRCUNVIS, B.C. ${ }^{2}$, RENESTO, E. ${ }^{2}$, MANGOLIN, C.A. ${ }^{2}$, MACHADO, M.F.P.S. ${ }^{2}$ e \\ TAKASUSUKI, M.C.C.R. ${ }^{2}$
}

\begin{abstract}
RESUMO - Crescente interesse tem se estabelecido para a análise da diversidade genética de espécies Conyza bonariensis, C. canadensis e C. sumatrensis, popularmente conhecidas como buva ou voadeira, que nos últimos anos vêm causando vários prejuízos nas lavouras do Brasil e do mundo, principalmente nas plantações de soja. A proposta do presente estudo foi estimar a variabilidade genética de amostras de $C$. sumatrensis provenientes da região noroeste do Estado do Paraná. A análise de isozimas em tecidos de folhas das plantas de C. sumatrensis foi realizada para estimar a variabilidade genética dentro de cada população e entre populações diferentes, no sentido de recomendar um tratamento diferencial ou uniforme para o controle dessas plantas daninhas na referida região. Foram analisados quatro sistemas enzimáticos (ACP, GPI, MDH e PGM) e detectados 10 locos com 10 alelos, os quais não apresentaram diversidade genética dentro e entre as populações analisadas, comprovado pela presença de apenas indivíduos homozigotos. As enzimas analisadas no presente estudo indicaram que as plantas das três regiões são geneticamente uniformes, e a uniformidade genética verificada para os referidos locos é um indicativo prévio de que é possível utilizar doses equivalentes do glifosato para controlar o crescimento desses biótipos.
\end{abstract}

Palavras-chave: isoenzimas, polimorfismo, Conyza, buva, variabilidade genética.

\begin{abstract}
There has been a growing interest for the analysis of genetic diversity of species Conyza bonariensis, C. canadensis and C. sumatrensis, popularly known as horseweed or motorboat, which in recent years have caused losses in several crops, mainly soybean, in Brazil and worldwide. The purpose of this study was to estimate the genetic samples of $\mathbf{C}$. sumatrensis from northwestern state of Paraná. Isozyme analysis in the tissue of C..sumatrensis leaves was performed to estimate the genetic variability within populations and among different populations to recommend a uniform or differential treatment for the control of these weeds in that region. Four enzymatic systems (ACP, GPI, MDH and PGM) were analyzed and 10 loci with 10 alleles detected, showing no genetic diversity within and between the populations analyzed, as shown by the presence of only homozygotes. The enzymes examined in this study indicated that the plants from the three regions are genetically uniform and that the uniformity observed for these genetic loci is a previous indication that equivalent doses of glyphosate can be applied to control the growth of these biotypes.
\end{abstract}

Keywords: isozymes, polymorphism, fleabane, Conyza, genetic diversity.

\section{INTRODUÇÃO}

As espécies de plantas daninhas Conyza canadenses, C. bonariensis e C. sumatrensis, conhecidas popularmente por "buvas" ou "voadeiras", têm-se destacado desde a década de 90 do século passado, por infestarem áreas abandonadas (terrenos baldios e margens de estradas), pastagens, culturas perenes, como citros e café, e lavouras anuais, como algodão, milho, soja e trigo (Thébaud \& Abbott, 1995). Em termos mundiais, essas espécies daninhas infestam mais de 40 culturas (Holm et al., 1997). Há relatos de que C. canadensis,

Recebido para publicação em 15.7.2013 e aprovado em 13.11.2013.

2 Universidade Estadual de Maringá, Paraná-PR, Brasil, <brunuagainst@hotmail.com>.

Planta Daninha, Viçosa-MG, v. 32, n. 1, p. 173-179, 2014 
na densidade de 150 plantas $\mathrm{m}^{-2}$, reduziu em $83 \%$ a produtividade de soja cultivada em semeadura direta (Bruce \& Kells, 1990). Em beterraba-açucareira, $C$. canadensis diminuiu a produtividade em $64 \%$ na média de dois anos e, também, inibiu o desenvolvimento de ramos novos em videira na ordem de 28\% (Holm et al.,1997). As espécies de Conyza são cosmopolitas, sendo mais encontradas em zonas temperadas do hemisfério norte (Holm et al., 1997) e regiões subtropicais do hemisfério sul, mas é pouco frequente em regiões tropicais (Kissmann \& Groth, 1999).

As espécies de Conyza, segundo Thébaud et al. (1995), são hexaploides autocompatíveis e aparentemente não são polinizadas por insetos, embora Smisek (1995) tenha relatado que os insetos visitam as flores abertas. As evidências de Thébaud et al. (1995) sugerem a ocorrência de autogamia ou polinização pelo vento, por meio de adaptações nos aquênios, os quais são formados por estruturas chamadas de pápus, embora os insetos visitem as flores abertas (Smisek, 1995).

O método de controle tradicional para as plantas de Conyza é por meio de aplicações de herbicida. A aplicação de glifosato é a principal ferramenta para o manejo dessas plantas daninhas; entretanto, plantas daninhas resistentes ao glifosato têm aparecido nas culturas como resultado do extensivo uso desse herbicida no controle dessas plantas (Perez-Jones et al., 2007). A evolução da resistência ao glifosato tem ocupado claramente o espaço dos agrossistemas; esse herbicida exerce forte e contínua pressão sobre as plantas daninhas. Em pomares de citros, foram identificados biótipos de $C$. canadensis resistentes ao glifosato (Christoffoleti et al., 2006; Montezuma et al., 2006; Moreira et al., 2007); o mesmo ocorre com $C$. bonariensis em áreas de soja transgênica (Vargas et al., 2007; Lamego \& Vidal, 2008). A ocorrência de biótipos resistentes aos herbicidas indica a necessidade de técnicas de manejo integrado de plantas daninhas.

Para realizar o manejo integrado de espécies de Conyza, é importante conhecer a diversidade genética das suas populações. A forma como as populações estão geneticamente estruturadas é uma informação importante para orientar o desenvolvimento de planos efetivos de controle das plantas daninhas, porque um dos fatores que podem contribuir para determinar respostas diferentes de plantas daninhas à aplicação de herbicidas é a variabilidade genética presente em populações das diferentes espécies. De acordo com Allendorf \& Luikart (2007), a existência de variabilidade genética em indivíduos de uma população aumenta a chance de alguns para responder diferentemente a alterações do meio ambiente, de modo que isso possa garantir a preservação da espécie. Assim, as populações de plantas daninhas com maior diversidade genética podem se constituir num obstáculo para o controle pelo fato de as plantas apresentarem respostas variáveis aos tipos e/ou concentrações diferentes de herbicidas. A alta variabilidade genética dentro de populações de plantas daninhas pode indicar significativa quantidade de variação genética para escapar dos efeitos do agente de controle e, também, pode favorecer a seleção de genótipos resistentes. Por outro lado, as plantas geneticamente uniformes ou com variabilidade genética baixa podem apresentar respostas uniformes aos efeitos do agente de controle.

Por isso, a proposta do presente estudo foi estimar a variabilidade genética de amostras de $C$. sumatrensis provenientes da região noroeste do Estado do Paraná. As amostras de buva dessa região foram coletadas e enviadas para o Herbário Uberlandense do Instituto de Biologia da Universidade Federal de Uberlândia, onde foram catalogadas e identificadas como sendo a espécie Conyza sumatrensis. A análise de isozimas em tecidos de folhas das plantas de C. sumatrensis foi feita para estimar a variabilidade genética dentro de cada população e entre populações diferentes, no sentido de recomendar um tratamento diferencial ou uniforme para o controle dessas plantas daninhas na referida região.

\section{MATERIAL E MÉTODOS}

As sementes coletadas de áreas rurais de três cidades da região noroeste do Estado do Paraná: Guarapuava, Astorga e Nova Esperança, em um total de 56 plantas por local (Figura 1), foram colocadas para germinar em casa de vegetação. 
Foram realizadas irrigações diárias até as plantas atingirem o florescimento pleno, quando foi realizado o corte delas para a confecção das unicatas.

Atualmente, as amostras coletadas para identificação encontram-se disponíveis no Herbário da Universidade Estadual de Maringá (HUEM, 2011), identificadas com os números: HUEM 21290, HUEM 21291, HUEM 21292, HUEM 21293 e HUEM 21294.
Após o brotamento da quarta folha, as plantas foram utilizadas na extração das isozimas. Pequenos brotos e folhas jovens foram coletados com o auxílio de uma pinça e colocados em tubos polipropileno de $1,5 \mathrm{~mL}$, juntamente com $20 \mu \mathrm{L}$ de solução de extração, e mantidos no gelo para a maceração (Tabela 1).

As amostras foram centrifugadas em centrifuga refrigerada Hettich Mikro 200 R, durante 30 minutos com $12.000 \mathrm{rpm}$, a $4{ }^{\circ} \mathrm{C}$.

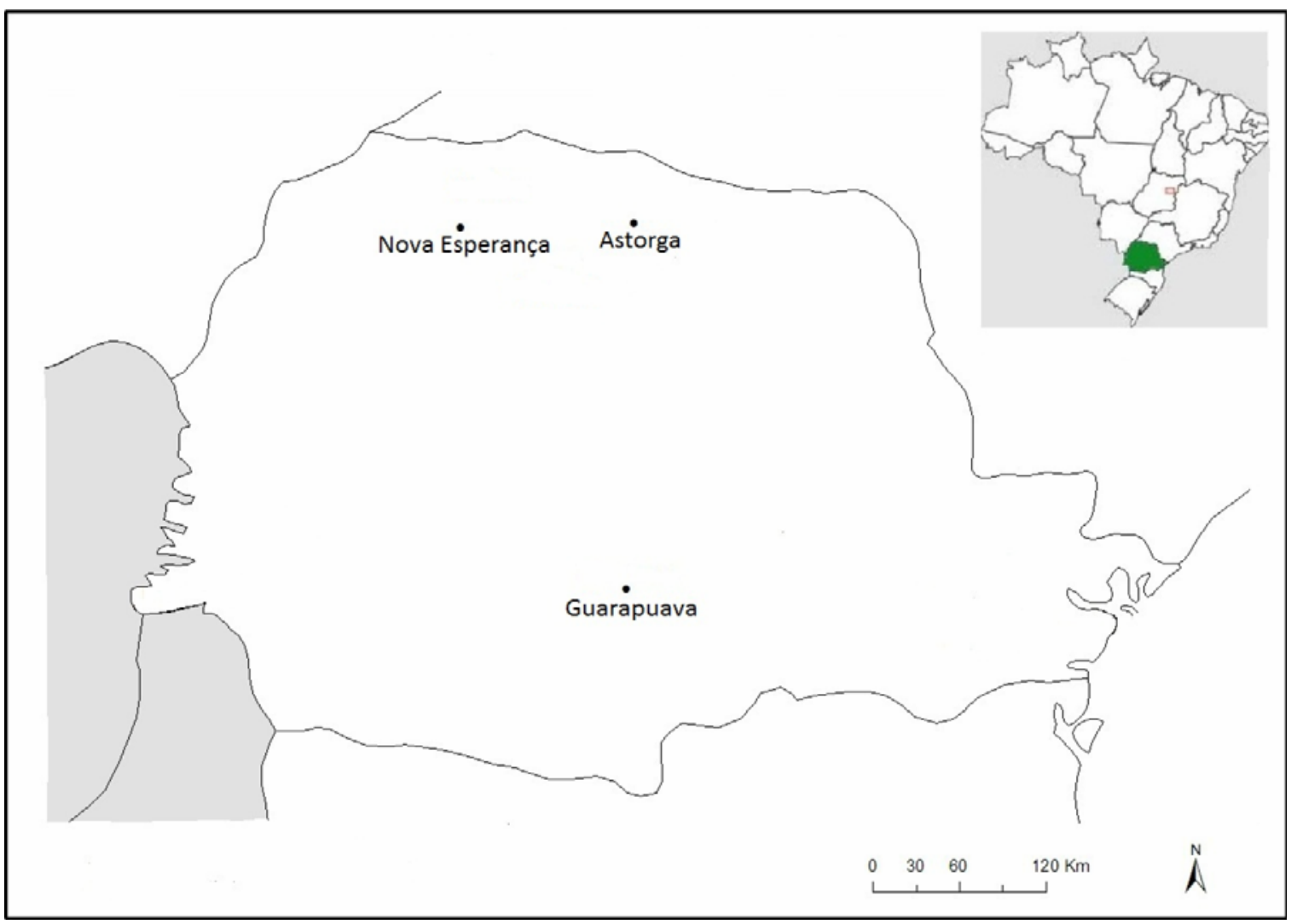

Figura 1 - Mapa de localização dos municípios do Estado do Paraná, onde foram coletados os acessos de Conyza sp.

Tabela 1 - Solução de extração utilizada para extrair as isoenzimas de brotos de folhas de Conyza sp

\begin{tabular}{|c|c|c|c|}
\hline Solução 1 & Solução 2 & Solução 3 & Solução 4 \\
\hline 0,05 PVP-40 & 0,04 g PVP - 40 & 0,04 g PVP - 40 & 0,04 g PVPP \\
\hline $10 \mu \mathrm{L}$ EDTA $1 \mathrm{mM}$ & $10 \mu \mathrm{L}$ EDTA $1 \mathrm{mM}$ & $10 \mu \mathrm{L}$ EDTA $1 \mathrm{mM}$ & $10 \mu \mathrm{L}$ EDTA $1 \mathrm{mM}$ \\
\hline $5 \mu \mathrm{L}$ B-mercaptoetanol & $10 \mu \mathrm{L}$ B-mercaptoetanol & $10 \mu \mathrm{L}$ B-mercaptoetanol & $10 \mu \mathrm{L}$ B-mercaptoetanol \\
\hline \multirow[t]{4}{*}{$\begin{array}{l}\text { Tampão Fosfato } 1 \mathrm{M} ; \mathrm{pH} \\
\text { 7,0, q.s.p } 1 \mathrm{~mL}\end{array}$} & $\begin{array}{l}\text { Tampão Tris-HCl 0,1M; pH } \\
8,0 \text {, q.s.p } 1 \mathrm{~mL}\end{array}$ & $\begin{array}{l}\text { Tampão Tris-HCl 0,1M; pH } \\
\text { 8,5, q.s.p } 1 \mathrm{~mL}\end{array}$ & $\begin{array}{l}\text { Tampão Tris-HCl 0,1 M; pH } \\
8,0 \text {, q.s.p } 1 \mathrm{~mL}\end{array}$ \\
\hline & 0,0038 g Borato de Sódio & & \\
\hline & 0,04 g Polietilenoglicol & & \\
\hline & 0,0038 g Cloreto de Sódio & & \\
\hline
\end{tabular}


Os sobrenadantes foram adsorvidos em papelfiltro (4 x $5 \mathrm{~mm}$ ) e aplicados em gel de amido 16\% (Penetrose 50®).

Para o preparo do gel, a suspensão de amido foi fervida em erlenmeyer, em bico de Bunsen, com agitação contínua, até ficar hialina. A solução foi derramada em uma placa de vidro com dimensões $18 \times 18$ x 0,6, permanecendo na geladeira por um período de 17 horas. Em seguida, a solução foi submetida à eletroforese horizontal em uma corrente contínua de $200 \mathrm{~V}$, com $50 \mathrm{~V}$ nas extremidades do gel, que corresponde aproximadamente a $20 \mathrm{~mA}$, verificada por meio de um voltímetro, contendo tampão de corrida Tris $(0,0103 \mathrm{M})$ e ácido cítrico $(0,0028 \mathrm{M}) \mathrm{pH}: 7,4$ na cuba. $\mathrm{O}$ mesmo tampão foi diluído 15 vezes, permitindo a obtenção e visualização das enzimas para análise fenotípica.

De doze sistemas enzimáticos analisados para avaliar a existência de diversidade genética em Conyza, apenas quatro foram revelados, MDH (Malato desidrogenase), ACP (Fosfatase ácida), GPI (Glucose-6-fosfato isomerase) e PGM (Fosfoglucomutase), onde foram testadas quatro soluções de extração, das quais apenas a solução 1 mostrou-se eficaz (Tabela 1).

Posteriormente à revelação dos quatro sistemas isoenzimáticos, os padrões de bandas foram analisados geneticamente. A interpretação genética foi baseada na estrutura quaternária das enzimas segundo Ward et al. (1992).

A análise feita permitiu estimar as frequências dos alelos e os parâmetros de diversidade genética, estimando a proporção de locos polimórficos; o número médio de alelos por loco $e$ heterozigosidade observada (Ho) e esperada (He); o afastamento do equilíbrio de Hardy-Weinberg; o coeficiente e endogamia $\left(\mathrm{F}_{\mathrm{IS}}\right)$; o déficit de heterozigotos $\left(\mathrm{F}_{\mathrm{IT}}\right)$; a proporção da diversidade genética entre as populações $\left(\mathrm{F}_{\mathrm{ST}}\right)$; e o fluxo gênico entre populações $(\mathrm{Nm})$ para os três acessos estudados, empregando o programa POPGENE 1.32 (Yeh et al., 1999).

\section{RESULTADOS E DISCUSSÃO}

A expressão enzimática dos alelos detectados neste estudo está ilustrada nos zimogramas representados pela Figura 2.
Visualiza-se que a enzima MDH foi a que apresentou maior número de locos (cinco), na qual se detectou a presença de três grupos diferentes de isozimas: $M D H$ microcorpos (mbMDH), $M D H$ mitocondrial (mt $M D H)$, e $M D H$ citosol ou solúvel (s $M D H)$. Uma mbMDH isozima foi evidente (mbMDH-5); dois locos foram evidentes para mtMDH isozimas (mtMdh-3 e $m t M d h-4)$; dois outros locos foram evidentes para isozimas mitocondriais (mtMdh-3 e $m t M d h-4)$; e mais dois locos para isozimas solúveis (s $M D H-1$ e $\mathrm{s} M D H-2)$. Também foi observada a presença de heterodímeros(hd*). Isso ocorre devido à organização estrutural complexa destas enzimas, que inclui a capacidade de produzir heterodímeros entre os produtos de alelos do mt Mdh e loco s $M D H$.

A enzima PGM foi a que apresentou menor número de loco (um), enquanto as enzimas GPI e ACP apresentaram número idêntico de locos (dois), todos monomórficos para todas as populações analisadas.

Das análises eletroforéticas obtidas, foi possivel identificar 10 locos e 10 alelos, entre os quatro sistemas isoenzimáticos estudados nas três populações de Conyza sp. Nesses 10 alelos detectados para esses sistemas enzimáticos não foi observada diversidade genética dentro e entre as populações analisadas. O mesmo resultado foi encontrado por Thébaud \& Abbott (1995) dentro de cada espécie analisada.

Esse resultado pode ser explicado por algumas hipóteses variadas, como o fato de esta espécie de planta ser autocompativel, sugerindo a ocorrência de autogamia.

Dessa forma, o pólen é liberado antes que os capítulos se abram, e a maioria de suas sementes $(80 \%)$, quando dispersas, germinam próximo à planta-mãe e, aparentemente, não são polinizadas por insetos (Smisek., 1995; Thébaud et al., 1996), sugerindo assim que essas populações analisadas sejam geneticamente próximas, evidenciando um ancestral em comum.

O predomínio de fenótipos homozigotos observado nas amostras de Conyza analisadas é esperado em razão da autocompatibilidade, sendo constatado esse fato por Smisek (1995), que detectou nível de cruzamento próximo a $4 \%$ e variando de 1,2 a $14,5 \%$. 

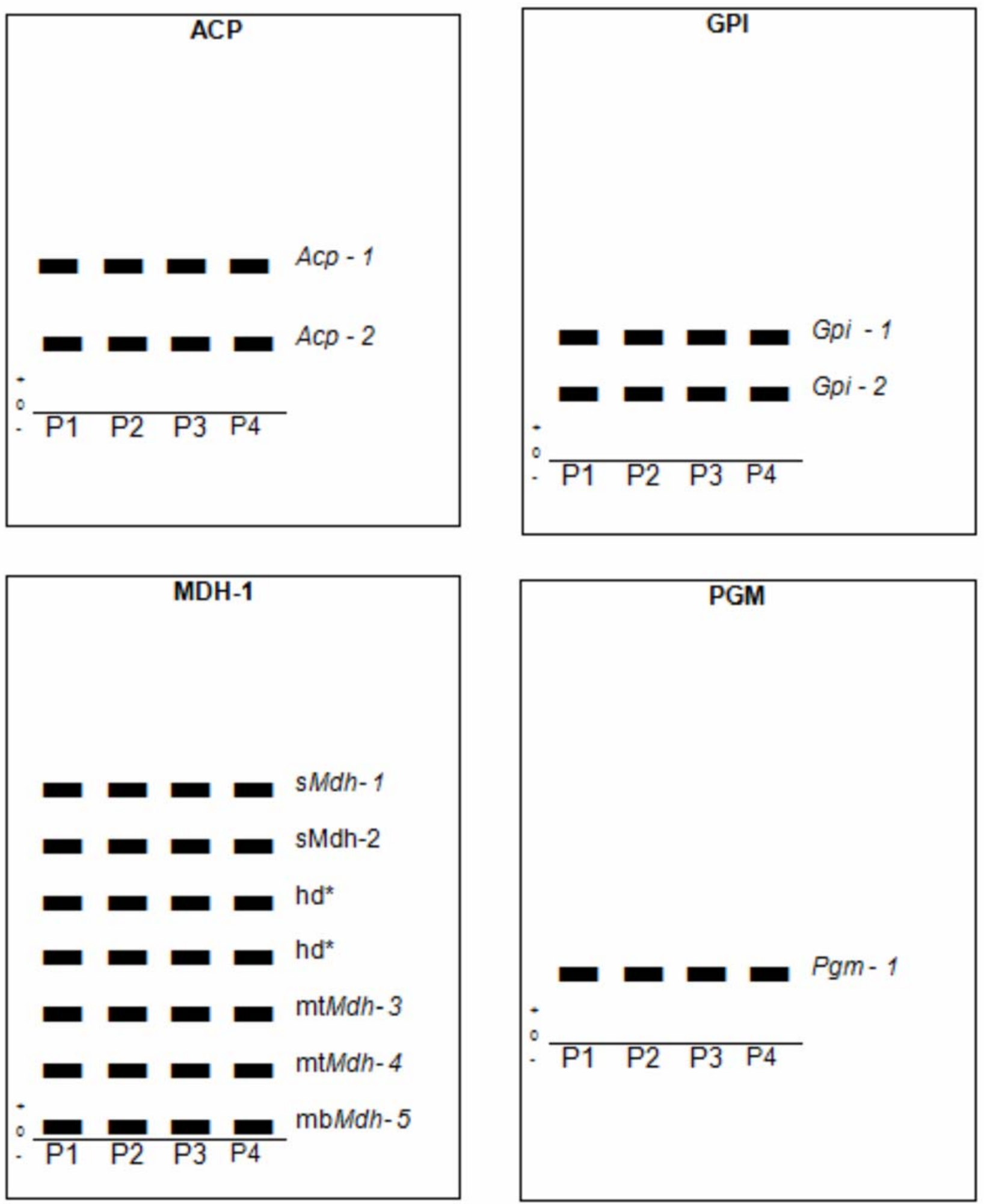

Figura 2 - Zimograma representado o padrão de bandas dos quatro sistemas isoenzimáticos analisados em gel de amido, com os seus respectivos loci, presentes nas populações (P1: população do município de Astorga; P2: população do município de Guarapuava; P3: população do município de Nova Esperança; todas do Estado do Paraná). 
Resultado semelhante foi encontrado por Souza \& Contel (2001), analisando genótipos de Helianthus annuus (Asteraceae) de 31 acessos e de cinco cultivares nos sistemas isoenzimáticos fosfoglicomutase (PGM), 6-fosfogliconato desidrogenase (PGD), fosfoglicoisomerase (PGI) e esterase (EST). Foram detectados um total de seis locos e 14 alelos para esses quatro sistemas, evidenciando baixo grau de diversidade genética, variando entre 0,003 e 0,418 . Isso indica uma grande semelhança entre esses materiais nos sistemas enzimáticos analisados.

No complexo Bidens pilosa (picão-preto), empregando 10 sistemas enzimáticos, foram revelados 16 locos, e, destes, somente três foram polimórficos. A diversidade genética, para esse complexo, avaliada por GromboneGuaratini et al. (2005), foi baixa, e o valor encontrado foi de $3,2 \%$ de locos polimórficos.

Acessos de Eichornia crassipes (aguapé) apresentaram similaridade genética de 90\%, considerada alta, o que se explica pela forma de propagação vegetativa, que diminui a possibilidade de recombinação genética (Cardoso et al., 2002).

Mori et al. (1999), trabalhando com Egeria najas na bacia hidrográfica do rio Paraná, analisaram os padrões isoenzimáticos das enzimas MDH, IDH, SKDH, ACP e AAT. Foram encontrados somente dois padrões distintos de bandas, que diferenciam os materiais genéticos e separaram os individuos em quatro classes distintas. Os padrões de isozimas pouco discriminaram diferenças entre eles, podendose concluir, por meio desses resultados, que pouca variabilidade genética estaria ocorrendo nas populações estudadas. Entretanto, para comprovar esses resultados, utilizaram-se também os procedimentos de eletroforese de DNA (técnica de RAPD). Em certos casos, as isozimas são ferramentas limitadas para discriminar diferenças entre indivíduos.

$\mathrm{Na}$ análise de grupamento, observou-se que a Egeria najas possui variabilidade genética, evidenciando que as populações são formadas por diversos genótipos com pequenas diferenças genéticas entre plantas. Os indivíduos foram separados por distâncias genéticas inferiores a 0,24 , ou seja, possuem similaridades genéticas superiores a 0,78 .
Por fim, estudos empregando isozimas (Barret, 1992) têm evidenciado que muitas populações de plantas daninhas contêm reduzida diversidade genética e que a estimativa da diversidade é idêntica tanto quando avaliada por meio de isozimas como quando avaliada com marcadores de DNA, como, por exemplo, RAPD e AFLP (Okuno et al., 1998; Pester et al., 2003). Contudo, no caso do gênero Conyza, é necessária uma análise mais aprofundada para constatar se existe variabilidade genética, uma vez que Ren et al. (2010) detectaram alta variabilidade genética, evidenciada pelo valor de $\mathrm{He}=0,385$, em 17 populações de Conyza sumatrensis da China, utilizando marcadores de ISSR.

Esses resultados obtidos para C. sumatrensis parecem paradoxais: pelo fato de organismos poliploides terem várias cópias do mesmo gene, eles têm mais probabilidade que os diploides de sofrerem mutações e de acumularem essas mutações ao longo do tempo, e, portanto, deveria se esperar que espécies de Conyza exibissem maior variabilidade genética.

Além disso, o fato de Conyza estar distribuída por vários continentes mostra que é uma espécie com alta adaptabilidade característica esta que depende diretamente da diversidade genética da espécie. Desse modo, C. sumatrensis deveria apresentar maior variabilidade do que a observada no presente experimento e no de Thébaud \& Abbott (1995). No entanto, é importante frisar que a frequente exposição a herbicidas pode levar à diminuição da heterozigosidade e que o processo de seleção de biótipos resistentes reduz ainda mais a heterozigosidade, implicando baixos níveis de diversidade genética.

A despeito de se conhecerem os fatores determinantes da ausência de polimorfismo na análise dos produtos dos 10 locos (sMDH-1, sMDH-2, mtMdh-3, mtMdh-4, mbMDH-5, Pgm-1, Gpi-1, Gpi-2, Acp-1, e Acp-2) nos biótipos das regiões de Guarapuava, Astorga e Nova Esperança, a uniformidade genética verificada para os referidos locos é um indicativo prévio de que é possivel utilizar doses equivalentes do glifosato para controlar o crescimento desses biótipos. Além disso, esses locos monomórficos podem ser usados como marcadores da estabilidade genética das plantas para os 
referidos locos, durante a evolução dos ciclos periódicos de seleção para o controle das infestações e de seleção de plantas resistentes ao glifosato, bem como na perspectiva de estudos futuros, a fim de verificar a ocorrência de resistência aos inibidores da acetolactato sintase.

\section{LITERATURA CITADA}

ALLENDORF, F. W.; LUIKART, G. Conservation and the genetics of populations. Massachusetts, Blackwell Publishing Maden, 2007. 642 p.

BARRET, S. C. H. Genetics of weed invasions. In: JAIN, S. K.; BOTSFORD, L. W. (Ed). Applied population biology. Dordrecht: Kluwer Academic Publishers, 1992. p. 91-119.

BRUCE, J. A.; KELLS, J. J. Horseweed (Conyza canadensis) control in no-tillage soybeans (Glycine max) with preplant and preemergence herbicides. Weed Technol., v. 4, n. 3, p. 642-647, 1990.

CARDOSO, L. R. et al. Variabilidade genética de acessos de aguapé coletados no estado de São Paulo. Planta Daninha, v. 20, p. 1-5, 2002. (Edição Especial)

CHRISTOFFOLETI, P. J. et al. Herbicidas alternativos para o controle de biótipos de Conyza bonariensis e C. canadensis supostamente resistentes ao herbicida glyphosate. In: CONGRESSO BRASILEIRO DA CIÊNCIA DAS PLANTAS DANINHAS, 25., 2006, Brasília.

Resumos... Brasília: SBCPD/UNB/Embrapa Cerrados, 2006. v. 25. p. 553-553.

GROMBONE-GUARATINI, M. T.; SEMIR, J.; SOLFERINI, V. N. Low Allozymic Variation in the Bidens pilosa L. Complex (Asteraceae). Biochem. System. Ecol., v. 43, n. 7/8, p. 335-345, 2005.

HOLM, L. G. World weeds: natural histories and distribution. Toronto: Wiley, 1997. p. 226-235.

KISSMANN, K. G.; GROTH, D. Plantas infestantes e nocivas. 2.ed. São Bernardo do Campo: Basf., 1999. p. 278-284.

LAMEGO, F. P.; VIDAL, R. A. Resistência ao Glyphosate em biótipos de Conyza bonariensis e Conyza canadensis no estado do Rio Grande do Sul, Brasil. Planta Daninha, v. 26, n. 2, p. 467-471, 2008.

MONTEZUMA, M. C. et al. Avaliação da suspeita de buva (C. bonariensis e C. canadensis) ao herbicida glyphosate em pomares de citros no estado de São Paulo. In: CONGRESSO BRASILEIRO DA CIÊNCIA DAS PLANTAS DANINHAS, 25., Brasília, 2006. Resumos... Brasília: SBCPD/UNB/ Embrapa Cerrados, 2006. v. 25. p. 564
MOREIRA, M. S. et al. Resistência de Conyza canadensis e C. bonariensis ao herbicida glyphosate. Planta Daninha, v. 25, n. 1, p. 157-164, 2007.

MORI, S. E. et al. Caracterização genética de populações de Egeria najas presentes no reservatório de Jupiá e rios afluentes. Planta Daninha, v. 17, n. 2, p. 217-225, 1999.

OKUNO, K. et al. Genetic diversity of central Asian and north Caucasian Aegilops species as revealed by RAPD markers. Genetics Res. Crop Evol., v. 45, n. 4, p. 289-394, 1998.

PESTER, T. A. et al. Genetic diversity of jointed goatgrass (Aegilops cylindrica) determined with RAPD and AFLP markers. Weed Sci., v. 51, n. 3, p. 287-293, 2003.

PEREZ-JONES, A. et al. Investigating the mechanisms of glyphosate resistance in Lolium multiflorum. Planta, v. 226, n. 2, p. 395-404, 2007.

REN, X. M.; LI, Q. X.; DING, Q. J. Genetic variation and spread pattern of invasive Conyza sumatrensis around China's Three Gorges Dam. Acta Oecol., v. 36, n. 5, p. 599-603, 2010.

SMISEK, A. J. J. The evolution of resistance to paraquat in populations of Erigeron canadensis L. 1995. $102 \mathrm{f}$.

Dissertação (Mestrado em Biologia-Ecologia) - University of Western Ontario, London, 1995.

SOUZA, S. F.; CONTEL, B. P. B. Análise da variabilidade de isoenzimas em acessos e cultivares de girassol. Pesq.

Agropec. Bras., v. 36, n. 5, p. 771-779, 2001.

THÉBAUD, C.; ABBOTT, R. J. Characterization of invasive Conyza species (Asteraceae) in Europe: quantitative trait and isozyme analysis. Am. J. Bot., v. 82, n. 3, p. 360-368, 1995.

THÉBAUD, C. et al. Assessing why two introduced Conyza differ in their ability to invade Mediterranean old fields. Ecology, v. 77, n. 3, p. 791-804, 1996.

VARGAS, L. et al. Buva (Conyza bonariensis) resistente ao Glyphosate na região sul do Brasil. Planta Daninha, v. 25, n. 3, p. 573-578, 2007.

WARD, R. D.; SKIBINSKI, D. O. F.; WOODWARK, M. Protein heterozygosity, protein structure, and taxonomic differentiation. Evol. Biol., v. 26, n. 1, p. 73-159, 1992.

YEH, F. C. et al. POPGENE, the user-friendly shareware for population genetic analysis. [1997]. Disponível em: $<$ http://www.ualberta.ca/ fyeh/faq.htm>. Acesso em: 20 jul. 2011.

Planta Daninha, Viçosa-MG, v. 32, n. 1, p. 173-179, 2014 